\title{
Street lighting design for a traditional city: a case study of Jesi, Italy
}

\author{
A. Srisuwan \\ Dipartimento di Energetica, Università Politecnica delle Marche, \\ Ancona, Italy
}

\begin{abstract}
Crimes rarely occur if potential offenders are aware that there are eyes on the street that can witness, report or intervene in their activities. Lighting has a major role in guarding against criminal assault on public streets at night. The lighting needs to illuminate more than just the actual lighting functions; it also shapes the face of the street and defines the residential environment as a "homely" atmosphere. The residential area in a traditional city is in particular considered in this study. Space syntax models spatial configurations of urban street configurations by using a connectivity graph representation. Such a configuration of connectivity identifies pedestrian access patterns and can be analyzed and selected in a study area. The illumination distribution is calculated and a lighting design framework is suggested.
\end{abstract}

Keywords: street lighting design, crime prevention, space syntax, traditional city.

\section{Introduction}

Since the 1990s, along with an increasing concern with outdoor lighting, cities have started to glitter more at night (Jankowski [1]). The cities have aimed to promote and expose more flux on the facets of landmarks, sculptures, monuments, buildings and structures (Lechner [2]). Consequently, illuminating public spaces at night has encouraged people to extend their activities until the night time. By means of the artificial lighting, environments in which pedestrians can quickly and accurately identify objects, and maintain orientation are created. Therefore, the people come and walk in the public spaces in the evening with a sense of safety and security. 
Furthermore, urban lighting has increased urban landscape and improves the overall nocturnal urban environment, which explores the various ways to enhance safety, aesthetics, and mobility of urban contents (Boyce [3]). It is because illumination has increased the ability to perceive and to identify environments after sunset. However, besides being visual clues of spatial perceptions, it is a definer of moods and behaviours of people passing by. Good lighting of a particular space can attract pedestrians to stop by and consider those objects in detail. It can affect the street in how it is perceived and used. Furthermore, it reveals the meaning of objects along the street, park and plaza including monuments and buildings and how those objects are perceived. Since then, night visibility has become one of means for completing urban night life to merge with peoples' needs. The multi-function space, such as communal squares, a promenade, a plaza, etc. has been constructed into the pedestrian network. Also, pedestrian lighting serves to provide safety and reveals its aesthetic and beauty to the city.

At present, most people who lived in urban areas are spending free time after finishing work or study, and their activities in public spaces extend from the daytime to the night time. The qualified need of the illumination of these public environments is increasing parallel with the number of residents. Thus, the level of illumination is increasingly important and should be considered.

With space syntax theory that has developed over the past three decades, it has several applications on urban configurations around the world. In this study it was used as a tool to select a particular street which has a high pedestrian movement. Jesi, in Italy, as a case study, is programmed from its spatial accessibility. Finally, the results from the analysis of the luminance values of a selected street are analyzed and then a street lighting plan is proposed.

\section{Background}

\subsection{The importance of Jesi, Italy, its history}

Jesi is a town in the province of Ancona in the Marche region, Italy. It is an area of 107 square kilometers with the 97 meters elevation above sea level. It is an agricultural and commercial center in the floodplain on the northern bank of the Esino River, 17 kilometers in distance from the mouth of the Adriatic Sea [4].

From its history, Jesi was probably one of many built Umbrian villages in the $4^{\text {th }}$ century $\mathrm{BC}$ to mark the boundary between the territory of the Piceno and Umbria (Fig 1). Jesi was invaded and conquered by the Senones (ancient Gaulish tribe) from France. The Senones had governed the coast area from Rimini to Ancona and settled "Sena Gallica" (Senigallia) as its capital. Its boundary is covered to the south of Esino River, then, Jesi was the last fortified place for the Gaulish tribe against Piceni. After being governed by Senones for more than 100 years, the Senones were defeated by the Romans in 247 BC. Since then Jesi became a colonial town of the Romans (colonia civium romanorum) under the name of Aesis (Cherubini [5]). 

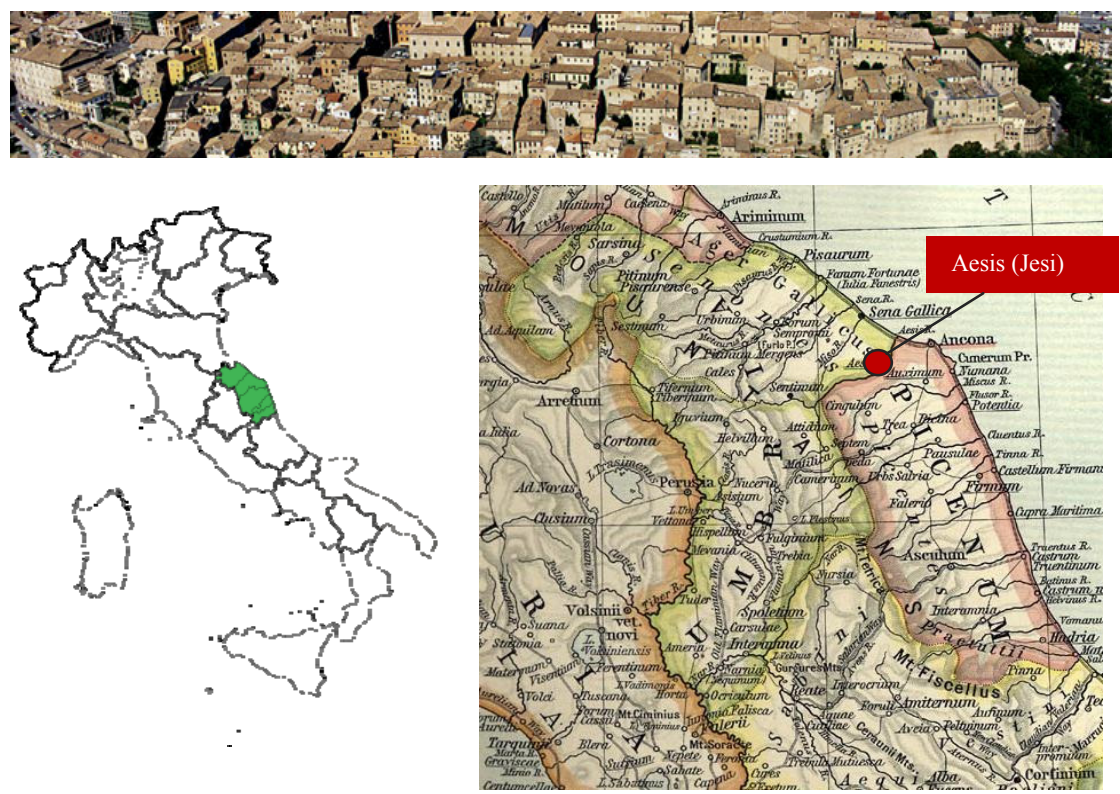

Figure 1: Location and aerial view of Jesi which was between Piceno and Umbria Region during the Roman period. The University of Texas at Austin [6].

When Italy became a part of the Byzantine Empire, Jesi became a diocese town in 680 until 1130, it had become an independent commune with autonomous government. During the 1200 s the city was succeeded by local aristocracy (feudalism). With an appointment of a cardinal vicar over the landlords before the authorized constitution in 1353, all of communes and lordships consequently came under control of the Pope.

Around 1470, the population decreased by plague spread out to Marc d'Ancona, therefore, there was immigration in 1471 from the Emila and Lombardia zone which still can be seen by its traces from the street name such as dei Lombardi, Costa dei Lombardi, Fiorenzuola, etc. At the end of the lordship and plague period, the city was to start reassembling in order and recover economy, demography and buildings including new construction of churches and palaces that spread out to the urban areas further outside the old wall until late 1700s.

The city remained under the dominion of the Church until the advent of the troop of Napoleon in 1797. Until 1808 with an annexation of Marche under Napoleon's kingdom of the Roman Republic (Repubblica Romana), Jesi became one of the capitals of the district department of Metauro (distretto del Dipartimento del Metauro). After the fall of Napoleon at Waterloo, Belgium and success of restoration in 1815, Jesi became autonomous and the unity of Italy among the municipalities in the province of Ancona [7]. 
Jesi has a long history and sophisticated experience of designed urban spaces through its history. Consequently, Jesi recognised the need to retain its appeal by exploiting the historic and contemporary cultural assets. Therefore, illumination design has increased and is found to be essential for reaching its aim of revealing the city's history importance in the present.

\subsection{Space syntax theory}

Hillier and Hanson published a syntactic theory for the pattern of space and interaction in the built environment in The Social Logic of Space in 1984. From that book they argued that buildings, towns, and cities have complex spatial properties that translate into sociological rules which affect how people relate to one another. They urged that space is not as the background to human activity, but as an intrinsic aspect of everything human beings do. Furthermore space seemed to identify structures which linked the social and the spatial. Consequently, space is able to give expression to social meanings. Within the framework on both the common physical and social ground in the city, space syntax theory and method has begun. Through the research team led by Bill Hillier and Hanson at the Bartlett School of Architecture and Planning, University College London, space syntax has developed since the late 1970s in reading urban configurations.

Space syntax is based on the concept of spatial configuration which means, in syntax terms, relations between spaces which take into account other relations in various spaces of a system. It can describe some aspects of how we use or experience space and to see how buildings and cities are organized in terms of geometric ideas. Moreover, in terms of relation between spaces, it can represent the inter-relations between the many spaces that make up the spatial layout of a building or a city. Then, space syntax is an alternative for quantifying and describing urban form influences on spatial formation by decoding a set of spatial properties of the layout (Hillier [8], Hillier and Hanson [9]) Therefore, space syntax is able to express the property of space in spatial configuration and distinguish social characteristics and their meanings that are imprinted and function in spatial layouts.

Space configuration measures of relation between spaces in graphs, and theorizes them in terms of their potential to embody or transmit social ideas, and then turns them into measures and representations of spatial structure by linking them to geometric representations of the system of spaces under examination. Providing a measurable scale from segregation to integration, enabled statistical comparison of different spatial forms across cultures, and investigated the average relations for the whole complex. Then, the space syntax program is a tool that presents the effect of spatial layout on functioning in the layout and is expressed through the computer program. Technically, it draws the longest line of the sight that is traced over every street segment in the layout. Then, certain descriptors of the layout are devised to measure an overlap counts as a connection. It is calculated how each street segment is connected in the layout. These descriptors (integration or segregation) can then be analyzed mathematically to predict spatial behavior without concerning any information 
on origins, destinations, or individual motivations (Penn [10]). Consequently, space syntax provides an assessment of the amount of pedestrian movement generated solely by the spatial configuration of the layout, independent of any land uses that may attract movement. The visually integrated spaces are the area which has result in high overlap counts of visual lines. Therefore, the integrated spaces are the places that contain high probability of people passing through, while the segregated spaces result in the converse.

Even though theory and method of space syntax has been leveled against on its lacks of sociological sophistication and complexity of real life situations, but it has published a great deal of development over the past two decades. This has been due to three factors largely; the wide range in application of space syntax into building and settlement types (Hanson, [11, 12]; Hillier, [8]; Peponis et al. [13], etc.) the development of sophisticated computer software that has allowed researchers to numerically capture differences in the configuration of spaces (Penn et al. [14]; Turner [15], etc.), and the organization of international symposia on space syntax research $(2009,2007, \ldots, 1997)$ (Dawson [16]). Results indicate that space syntax is still a useful tool in analyzing spatial formations in built environments.

\section{Research scope and procedure}

This research is focused on pedestrians who get an effect from luminance in old urban areas of Jesi, Italy mainly, due to these people using urban space in their everyday lives and will receive the most benefits of appropriate lighting in an urban area.

In order to understand how the spatial layout of buildings and cities influences the human movement and social interaction, a space syntax program is introduced as a tool of examination. Since a space syntax program can represent the connected spaces as a matrix, then, the program simulated the connected accessibility by its mathematical properties. The layout of Jesi was drawn and evaluated with its spatial connectivity by UCL Depthmap software. An axial map is created and fed into a program that executes the required calculations. The results revealed the segregated and integrated areas. The area that carries the highest probability of people passing through was selected as a case study in this study. After that the measurement of lighting of the selected area was calculated, analyzed and finally, the proposed street lighting plan is suggested.

\section{Results and analysis}

\subsection{Space syntax analysis}

An axial map of an old urban area of Jesi was produced using UCL Dethmap software. Once an axial map is obtained, the calculation of spatial connectivity is begun. Firstly, the study considers the parameter of integrated value. An integration analysis is indicated by color from the most segregated area in blue to the most integrated area in red. The latter analysis reveals the most accessible 
area in red and lesser accessibility in blue. Moreover the integrated value is analyzed, the degree of correlation between global state measure and local state measure is concerned.

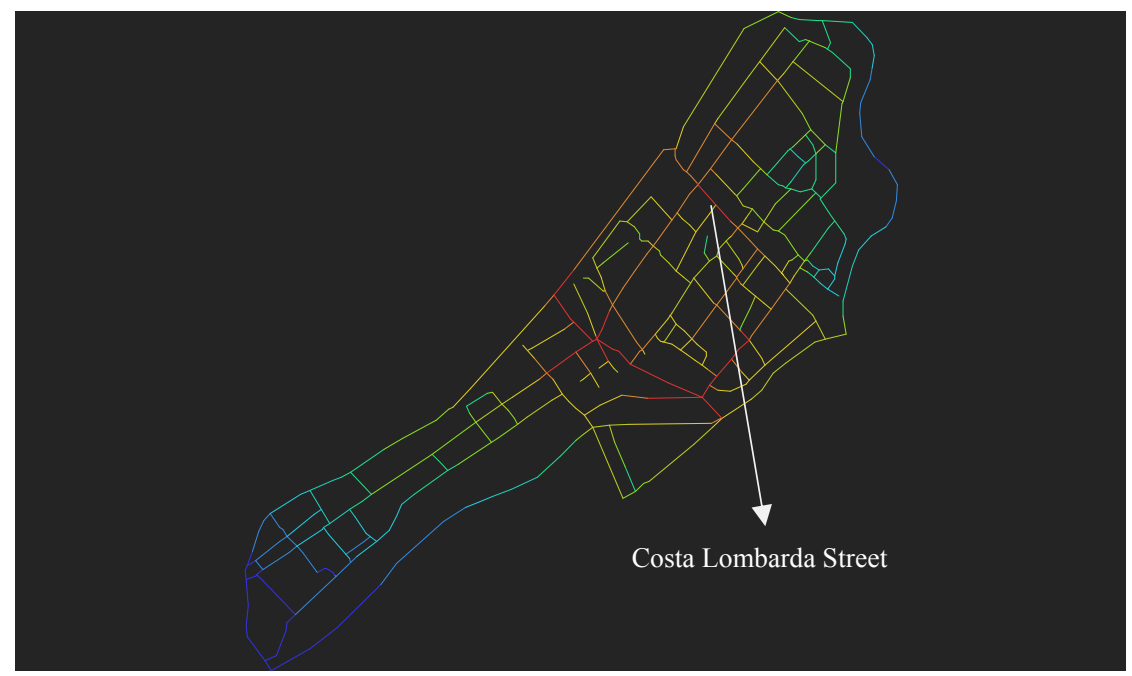

Figure 2: $\quad$ Axial map and an integration value in an old city of Jesi.

The correlation between integration (global state) and connectivity (local state) shows that the whole layout of the city cannot be readable from the parts $\left(\mathrm{R}^{2}=0.085\right)$. Furthermore, the result is also reveals that Jesi downtown produces an accessibility of a space in through-movement pattern rather than to-movement pattern $\left(\mathrm{R}^{2}=0.183\right)$. Consequently, choice parameter which indicates movements of inhabitants who have better knowledge of the layout than strangers is used as the criteria of locating the case study area. Finally, Costa Lombarda Street which contains both a high integration degree and choice value is selected as a case study for illumination design.

\subsection{Land use, characteristics and luminous environment on Costa Lombarda Street}

The Costa Lombarda is located on the eastern part of an old city area of Jesi. It partly slopes down from the north to the south with the length of 142.06 meters and approximately 20 meters slope difference from the origin of the street to another end of the street. There are many streets that are separated from and merged into this street including a small plaza and the main plaza of the city which connects at one end of the street. Due to its settlement since the medieval period, the street is not in a continuous straight line. Furthermore, the street's width varies differently along the street. The broadest area is 6.06 meters at the beginning and the narrowest area is set at the middle of the street (2.42 meters).

The Costa Lombarda street is the street that links all sub streets in that area altogether and is filled with the residential units in a block along both sides of the 
street. It is in walking range of the municipal office (commune) and some professional schools that fill the street with people in the daytime. Furthermore, by the street's location, it is surrounded by the facilities of the city such as a sport complex, theater, museum, palace and plaza, etc. which complement to the lively area both in the daytime and nocturnal time.

\subsection{Analysis of the luminance measurement}

Overall of the luminaries on the Costa Lombarda Street, it has installed 10 lamps at the building wall with unequal distance in each other and an unequal level of height. There are 8 lamps on the east side and 2 lamps on another side of the street. Most of the lamps are installed at a corner of the buildings or at an intersection between other streets and Costa Lombarda Street (Fig 3). The light sources used for Costa Lombarda Street are low pressure sodium (SOX) discharge lamps 70 watt. Since this study is focused on a pedestrian walkway, therefore, the angle between light source and pedestrian surface is considered illumination at 3 positions which are beneath its lamp point, across the street, and between beside lamps. Therefore, the results of pavement luminance at each point of all 10 lamps are measured and compared to the calculated value which is disposed by the point source formula. Simons [17].

$$
\mathrm{E}=\underline{\mathrm{I}}_{2} \underline{\operatorname{Cos}^{3} \gamma}
$$

where $\mathrm{E}=$ illuminance at the receiving surface

$\mathrm{I}_{\gamma}=$ the luminous intensity at the source when viewed from the direction of the receiving surface

$\gamma=$ the angle between a line from the source to the surface and a vector normal (perpendicular) to the receiving surface

$\mathrm{H}=$ the distance from the source to the surface

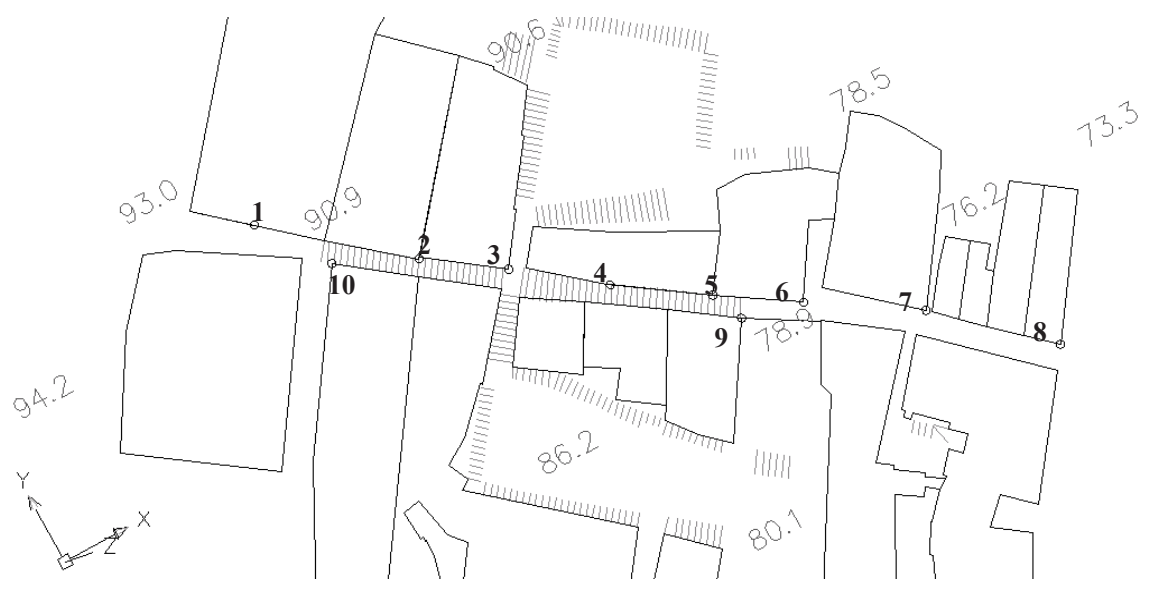

Figure 3: Characteristic of the Costa Lombarda street and its lamps fixture points. 
The calculation from its specification of light fixture shows that a light source produced enough luminance value that lay beyond the standard level of pedestrian illumination (CIE standard $=50-100-150$ lux). However, some of the light emitting from the theory method also shows that a luminous flux across the street falls into an under-standard level. Furthermore, the luminous flux that is transferred to the next lamps is of quite low value because of distance of settings which is a little bit far apart from each other. It is further revealed that there are pools of darkness at a distance between adjacent lit areas (between fixtures 1 and 2 and between lamp 6 and 7).

Table 1: Luminance value at each point of lamps on Costa Lombarda street (Measured on 8 January 2011 at 20.00).

\begin{tabular}{|c|c|c|c|c|c|c|c|c|}
\hline \multirow{3}{*}{ No } & \multirow{3}{*}{$\begin{array}{l}\text { Height } \\
(\mathrm{m})\end{array}$} & \multirow{3}{*}{$\begin{array}{l}\text { Street } \\
\text { Width }\end{array}$} & \multicolumn{6}{|c|}{ Illuminance(E) (lux) } \\
\hline & & & \multicolumn{2}{|c|}{$\begin{array}{l}\text { Beneath its } \\
\text { lamp }\end{array}$} & \multicolumn{2}{|c|}{$\begin{array}{l}\text { Opposite side of } \\
\text { street }\end{array}$} & \multicolumn{2}{|c|}{$\begin{array}{l}\text { Beam at the mid-length } \\
\text { between lamp }\end{array}$} \\
\hline & & & Mea & Cal & $\begin{array}{l}\text { Measure } \\
(\Delta \text { beneath })\end{array}$ & Cal & $\begin{array}{c}\text { Measure } \\
(\Delta \text { beneath) }\end{array}$ & $\mathrm{Cal}$ \\
\hline L 1 & 4.07 & 4.54 & 12.9 & 99.8 & $5(38.8)$ & 36.5 & $3.3(25.6)$ & 0.5 \\
\hline L 2 & 4.35 & 2.71 & 10.2 & 87.3 & $7.6(74.5)$ & 56.2 & $3.2(31.4)$ & 5.7 \\
\hline L 3 & 4.68 & 3.07 & 10.1 & 75.1 & $5(49.5)$ & 46.6 & $3.5(34.6)$ & 4.0 \\
\hline L 4 & 4.53 & 2.94 & 10.6 & 80.4 & $5.7(53.8)$ & 50.6 & $3.3(31.1)$ & 3.6 \\
\hline L 5 & 4.72 & 2.97 & 10.7 & 73.9 & $7.8(72.9)$ & 77.2 & $7.3(68.2)$ & 4.6 \\
\hline L 6 & 4.30 & 2.78 & 10.7 & 89.2 & $5.6(52.3)$ & 56.1 & 2.1(19.6) & 1.2 \\
\hline L 7 & 4.27 & 3.85 & 14.1 & 90.6 & $8.2(58.2)$ & 44.6 & $2.8(19.9)$ & 3.5 \\
\hline L 8 & 4.64 & 3.9 & 9.5 & 76.5 & $4.0(42.1)$ & 41.0 & - & - \\
\hline L 9 & 3.00 & 3.11 & 13,3 & 183.2 & $6,1(45.9)$ & 72.1 & NA & NA \\
\hline L10 & 4,38 & 3.22 & 10.1 & 86.0 & $4.6(45.5)$ & 49.9 & - & - \\
\hline$x$ & 4.29 & 3.31 & 11.2 & 94.2 & $6.0(\mathbf{5 3 . 3})$ & 53.1 & $3.6(33.0)$ & 2.9 \\
\hline
\end{tabular}

Nevertheless, table 1 shows that the luminance values of measuring and calculating are totally different. The experimental results contain much lower value than their calculations and also inferior to CIE standard for pedestrian activity. It is possible to assume that its low intensity result is caused by its covering of dirt, its lamp life nearly terminated, and materials which reflect light beam at low percentage on both of the buildings' wall and pavement. The residential area of the medieval city in Jesi is constructed of a thick brick with brown or dark brown color which can be reflected by an incident illuminant 
beam of only 35-40\%. Furthermore, the houses that set along on the street do not add to an increase in illumination to the street because of their function as a storeroom without windows on a ground floor and living function on the above floor. Consequently, there is no addition lighting from the living areas to penetrate to the street. Additionally, when comparing luminance intensity between luminaries at nearly the same width of the street (lamp 3 and lamp 9, and lamp 7 and lamp 8), it is found that a light source which is posted closer to the ground floor gives more luminance intensity than a higher posting. Furthermore, when considering the luminance beam that delivers to the opposite side of the street and the middle length between lamps in a horizontal line, it appeared that the luminance flux transfers its intensity about 50\% at plane 90 degrees of light source $\left(\mathrm{C}=90^{\circ}\right)$ and $30 \%$ at plane 180 degrees $\left(\mathrm{C}=180^{\circ}\right)$ respectively. Even though the amount of illuminant of measurement and calculation are different but the pattern of decreasing luminance flux across the street is decreased at the same proportion at $50 \%$. In addition, it is important to note that an irregular pattern of street also effect illuminant. Because of nongeometric streets then, there are some buildings that obstructed the luminous distant streak which is needed to consider on case by case basis.

\subsection{Street-luminance suggestion}

A well design lighting system for residential areas should accomplish a security purpose for the residents and people passing by at night. For reaching a secured residential area, the brightness of the lighting and the extent of luminance beam are important. The brightness of the area and its neighborhood affects how well the criminal can be seen and how exposed he feels. The brightness of the lighting guarantees a person's ability to detect and recognize other people. In addition, the extent of light beam is helped in which anything can be seen beyond the range of the area lit. Areas will likely always have people in them. The lighting beam controls the extent to which a criminal can be sure anybody is watching. Therefore, the people in the area or overlooking the area from adjacent buildings are able to detect the presence of others and recognize their intentions and actions at a distance.

From the result of measuring it is shown that a quantity of luminance on Costa Lombarda Street does not provide enough luminance for pedestrians who are passing by, and guarantee safety for the residents. For designing lighting illumination to the area of Costa Lombarda Street, it can be done in several ways. Firstly, maintenance lighting fixtures need to be cleaned to let it transfer light to the objects as intensive as its design. Later, the building's façade that line parallel to the street need to be cleaned or the walls painted a brighter color and pavement lightened for gaining more reflection. On one hand, the lamp's height should be dropped, that would help on increasing luminance on the surface. Then, the new prediction of measurement is done under an assumption that a luminance flux will be increased at 50\% across the street and $30 \%$ between lamps for prediction measurement parallel with a formula calculation (table 2).On the other hand, number of lighting fixture need to be increased, especially at the dark pool area to increase confident detection and recognition to 
22 Lighting in Engineering, Architecture and the Environment

Table 2: $\quad$ Estimated luminance value of reduced height of lamps at each point on Costa Lombarda Street.

\begin{tabular}{|c|c|c|c|c|c|c|c|c|}
\hline \multirow{3}{*}{ No. } & \multirow{3}{*}{$\begin{array}{l}\text { Height } \\
\text { (m) }\end{array}$} & \multirow{3}{*}{$\begin{array}{l}\text { Street } \\
\text { Width }\end{array}$} & \multicolumn{6}{|c|}{ Predicted Illuminance (E) (lux) } \\
\hline & & & \multicolumn{2}{|c|}{$\begin{array}{l}\text { Beneath its } \\
\text { lamp }\end{array}$} & \multicolumn{2}{|c|}{$\begin{array}{c}\text { Opposite side of } \\
\text { street }\end{array}$} & \multicolumn{2}{|c|}{$\begin{array}{l}\text { Beam at the mid-length } \\
\text { between lamp }\end{array}$} \\
\hline & & & Mea & Cal & Mea & Cal & Mea & $\mathrm{Cal}$ \\
\hline L 1 & 3.07 & 4.54 & 19.35 & 175.48 & 7.50 & 37.35 & 4.29 & 0.05 \\
\hline L 2 & 3.35 & 2.71 & 15.30 & 147.24 & 11.40 & 72.82 & 4.16 & 0.82 \\
\hline L 3 & 3.68 & 3.07 & 15.15 & 121.46 & 7.50 & 58.55 & 4.55 & 0.57 \\
\hline L 4 & 3.53 & 2.94 & 15.90 & 132.37 & 8.55 & 63.48 & 4.29 & 0.49 \\
\hline L 5 & 3.72 & 2.97 & 16.05 & 119.00 & 11.70 & 60.31 & 9.49 & 0.50 \\
\hline L 6 & 3.30 & 2.78 & 16.05 & 151.56 & 8.40 & 72.55 & 2.73 & 0.13 \\
\hline L 7 & 3.27 & 3.85 & 21.15 & 154.64 & 12.30 & 50.00 & 3.64 & 0.43 \\
\hline L 8 & 3.64 & 3.9 & 14.25 & 124.21 & 6.00 & 47.42 & - & - \\
\hline L 9 & 3.00 & 3.11 & 19.95 & 183.17 & 9.15 & 34.94 & NA & NA \\
\hline L10 & 3,38 & 3.22 & 15.15 & 144.30 & 6.90 & 61.19 & - & - \\
\hline$x$ & 3,39 & 3.31 & 16.83 & 145.34 & 8.94 & 55.86 & 4.74 & 0.43 \\
\hline
\end{tabular}

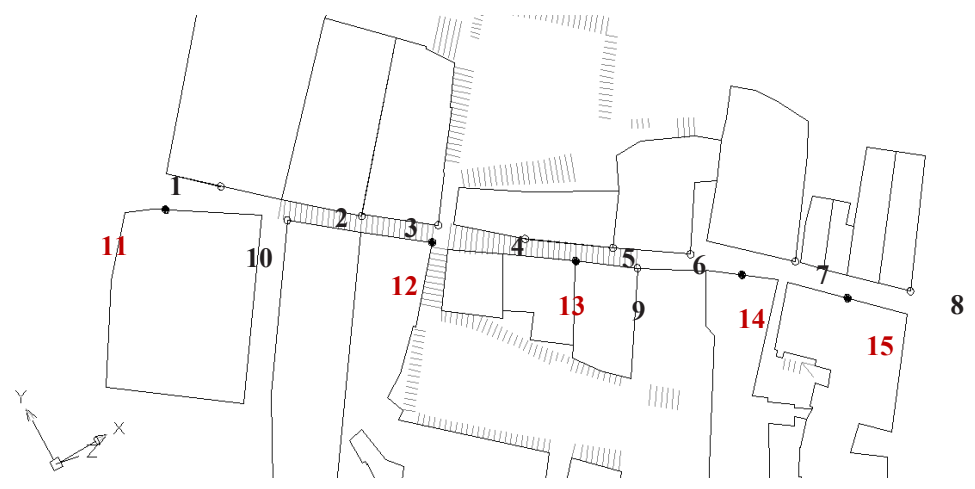

Figure 4: Suggestion of addition luminaries' position on Costa Lombard Street.

pedestrian visibility. The study has suggested adding5 more lighting fixtures on the side of lamp 9 and 10 as shown in figure 4 at the legend of 11-15. 
Nevertheless, providing enough luminance does not alone guarantee good residential lighting. Another important concern of good lighting is the physical characteristic of the targeted area. Therefore, besides calculating luminance to serve enough security purpose, lighting engineers should study and understand areas in parallel, especially street lighting design of a traditional city whose streets are not in a regular angle throughout the line. Furthermore, the luminaries themselves, which produce yellow/orange light, make residents difficult to distinguish new-comers and colors of objects. It would be better if we could switch to white light luminaries instead.

\section{Conclusion}

This study discusses urban environments and spaces for providing an appropriate street lighting design. The space syntax model is introduced to analyse and sort out the most accessible street to pedestrians in Jesi. The results from space syntax program and illuminance value in the selected area are analyzed. The illuminance values indicate that street lighting on the case study is inappropriate in pedestrian movement and visibility and a suggestion framework is required.

\section{Acknowledgement}

This work is financially supported by the MIUR (Ministry of Education, University and Research) in the Italian National Research Programme, PRIN; 2008.

\section{References}

[1] Jankowski W. Lighting exteriors and landscapes. New York: PBC Int. Inc. 1993.

[2] Lechner, Norbert. Heating, cooling, lighting: design methods for architects. $2^{\text {nd }}$ edition. New York: John Wiley. 2001.

[3] Boyce, Peter R. Security lighting: what we know and what we don't. Lighting Magazine, 5(6): pp. 12-18. 1991.

[4] Wikimedia Foundation, Inc, http://it.wikipedia.org/wiki/Jesi.

[5] Cherubini Alvise. 2005, 3 July. "Jesi: aspetti e suggestion della città antica." Settimanale d'informazione: p.3.

[6] The University of Texas at Austin, http://www.lib.utexas.edu/maps/ historical/shepherd_1911/shepherd-c-026-027.jpg.

[7] Immobiliare Azzurra s.r.l., http://www.immobiliareazzurra.com/Jesi.htm

[8] Hillier B., Space is the machine: A Configurational Theory of Architecture. Cambridge: Cambridge University Press. 1996.

[9] Hillier B., Hanson J, The Social Logic of Space. New York: Cambridge University Press. 1984.

[10] Penn Alan., Space Syntax and spatial cognition - Or why the axial line? Environment and Behavior January 35, pp. 30-65, 2003. 
24 Lighting in Engineering, Architecture and the Environment

[11] Hanson J., Deconstructing architects 'houses'. Environment and Planning B. 21, pp. 675-705, 1994.

[12] Hanson J., Decoding Houses and Homes. Cambridge: Cambridge University Press. 1998.

[13] Peponis, J., Ross, C., Rashid, M., The structure of urban space, movement and co-presence: the case for Atlanta. Geoforum. 28 (3-4), pp: 341-358, 1997.

[14] Penn, A., Hillier, B., Banister, D., Xu, J., Configurational modeling of urban movement networks. Environment and Planning. B 25 (1), pp 59-84, 1998.

[15] Turner, A., Depthmap: a program to perform visibility graph analysis. Proceedings of $3^{\text {rd }}$ International Symposium on Space Syntax, Georgia Institute of Technology, pp: 31.1 - 31.9, 2001.

[16] Dawson Peter C. Space Syntax analysis of Central Inuit snow houses. Journal of Anthropological Archaeology. 21, pp. 464-480. 2002.

[17] Simons R. H. and A. R. Bean. Lighting Engineering: applied calculations. Oxford: Architectural Press. 2001. 